\title{
A CONTABILIDADE A SERVIÇO DA DECISÃO
}

\section{ROGER R. CRANE E JOHN W. MCEACHREN}

E a contabilidade instrumento obsoleto de administração, ou linguagem adaptável às novas descobertas científicas que afetam o processo de decisões administrativas ?

Quem quer que tenha estudado a história da emprêsa sabe que, ao longo dos tempos, a contabilidade tem feito parte integrante do processo de decisão. Nos últimos anos, porém, as teorias científicas referentes a êsse processo vêm ganhando considerável prestígio e vários autores têm salientado que isto criou a necessidade de obtenção de novas informações rotineiras na prática de negócios (1). Alguns dêstes cientistas, ao indagar se o atual sistema contábil seria capaz de fornecer essas informações, manifestaram a respeito sérias dúvidas. Examinaremos, neste artigo, não só esta questã̃o, mas, também, a fim de colocar em perspectiva êstes novos desenvolvimentos, analisaremos o papel presente e futuro da contabilidade nas decisões administrativas.

O cientista, seja êle o matemático, o físico ou o antropólogo, é um recém-chegado ao campo da decisão. Ele sente, entretanto, grande confiança em sua capacidade de ajudar, tal-

ROGER R. CRANE - Sócio de «Touche, Ross, Bailey \& Smart», «Division of Management Sciences», New York, U.S.A.

JOHN W. McEACHREN - Sócio Dirigente de «Touche, Ross, Bailey \& Smart», New York, U.S.A.

(1) Vide, por exemplo, «Guides to Inventory Policy», de John Magee, Harvard Business Review, janeiro-fevereiro $1956 \mathrm{e}$ «Decision-Making in the Age of Automation», de Melvin Hurni, Harvard Business Review, setembro-outubro 1955. 
vez de criar novas doutrinas e métodos e mesmo de promulgar novas leis. Tem grande voracidade de informações e dados de custos de tôda a espécie. Estes dados e informações não estão, muitas vêzes, à mão; isto é suficiente para dar ao cientista a impressão de que a contabilidade é uma fonte inadequada de dados necessários; êle pensa que talvez esteja obsoleto e que deveria ser criado um sistema nôvo ou suplementar de coleta de informações.

A aplicação crescente das ciências da administração à emprêsa certamente afetará, de alguma forma, o sistema contábil. Mas o problema que a administração de cúpula depara de adaptar o cientista à organização e suas atividades será mais fàcilmente resolvido se houver melhor compreensão de como a contabilidade e as ciências administrativas podem trabalhar em conjunto.

\section{O que é a Contabilidade}

Todos podem entender que, mesmo numa pequena mercearia, haja necessidade de contabilizar as atividades financeiras, em particular nestes dias de complicadas leis fiscais. Em relação às emprêsas cujas ações são subscritas pelo grande público, todos sabem que êsses registros financeiros são exigidos por lei, para informação dos interessados. Muito poucas pessoas, porém, têm uma noção clara do que é ou pode ser a contabilidade.

Contabilidade é um sistema ordenado, destinado a registrar, de forma tão realista e clara quanto possível, as atividades que afetam a posição financeira de uma emprêsa. Os atuais conceitos contábeis são o resultado de centenas de anos de experiência de administradores com problemas de negó cios. Esta experiência se reflete de vários modos na elaboração do sistema. A contabilidade é, literalmente, uma linguagem própria e, como qualquer linguagem, deve ser cuidadosamente estudada, até mesmo vivida, para ser entendida.

De certa forma, o sistema contábil é um meio de contrôle, um dispositivo de alarme. Esse sistema fornece informações 
através das quais a administração é alertada quanto a tendências adversas, isto é, àquilo que não vai bem. As informações são registradas de forma rotineira e, quando preparadas em tempo hábil, quando a elas se aplicam orçamentos e padrões e quando os dados são representativos, a administração da emprêsa tem a seu dispor uma apresentação eficaz da dinâmica do negócio.

Como um sistema rotineiro, a contabilidade pode, ao mesmo tempo, dar sinais de alarme e fornecer informações que indiquem as providências necessárias para corrigir a tendência adversa, ou, em outros casos, propiciar dados adicionais que serão preparados e exigidos em separado. Preparar contínua e rotineiramente tôdas estas informações pode bem representar um desperdício. Em outras palavras, na elaboração de um sistema contábil, é o bom-senso que determina onde traçar a linha entre dados de utilidade diária - que devem ser preparados rotineiramente - e informações que serão colhidas sòmente quando uma situação especial o requeira. Isto não significa, porém, que estas últimas não sejam informações contábeis.

Pode ser que o cientista tenha a tendência de ver a contabilidade como aquela das demonstrações financeiras mais importantes. Este é um conceito muito restrito. Os dados contábeis podem ser preparados pelo mestre, apontador, inspetor de linha, encarregado do planejamento ou programação, encarregado de pedidos etc. De fato, a contabilidade inclui qualquer informação que possa ser traduzida em unidades físicas ou monetárias e esteja relacionada ao cuidado e uso dos recursos físicos, monetários ou de pessoal de uma emprêsa.

\section{Novas Informações para o Processo de Decisão}

A maioria das novas teorias científicas que afetam as informações rotineiras utilizadas pela emprêsa se centralizou nas operações de fabricação, como, por exemplo, na programação da produção, contrôle de estoque e manutenção ou re- 
novação de equipamento, e em teorias tais como a do uso do esfôrço de venda (2).

A teoria "científica" de uma atividade empresarial nada mais é do que uma teoria comum, pois representa as idéias de uma pessoa ou grupo de pessoas sôbre o funcionamento dessa atividade. Num certo sentido, porém, mais do que a grande parte das teorias, a teoria científica deve ser apresentada em linguagem precisa (muitas vêzes, embora nem sempre, em símbolos matemáticos) e sua precisão deve ser provável mediante aplicação à situação que pretende descrever. Qual é o valor da teoria, científica ou não científica? É uma tentativa de reconhecer relações entre fenômenos observáveis, como por exemplo, entre a utilização de uma certa máquina e os lucros brutos, ou entre a procura, a quantidade de novos pedidos, o nível de estoque e o custo total da operação do estoque. As teorias científicas sôbre o processo de decisão contribuem para o melhor entendimento das atividades $\mathrm{e}$ podem, mesmo, fornecer informações que não seriam obteníveis de outra forma.

A "Harvard Business Review" publicou, há algum tempo, um artigo em que a programação matemática é assim descrita : "Em muitas situações, a programação é o único modo prático de obter certas informações sôbre custos e lucros que são necessárias ao desenvolvimento de diretrizes mercadológicas, ao equilíbrio do equipamento de produção, à elaboração de planos de investimento e à obtenção de decisões

(2) Op. Cit. em (1) e também «Mathematical Methods in Management Programming», Melvin Salveson, «Proceedings of the Conference on Operations Research in Production and Inventory Control», Case Institute of Technology, janeiro 1954. «Optimal Distribution of Effort», B. O. Koopman, Journal of the Operations Research Society of America, fevereiro 1953. «Optimal Estimation of Executive Compensation by Linear Programming», Charnes, Cooper and Ferguson, Management Science, outubro 1956. «Capital Equipment Analysis: The Required Rate of Profit», Byron J. Gordon e Eli Shapiro, Management Science, outubro 1956. «Production Scheduling for an Arbitrary Number of Periods. Given the Sales Forecast in the Form of a Probability Distribution». Gunnar Dannerstedt, Journal of the Operations Research Society of America, agôsto 1955. 
racionais em relação a muitas espécies de problemas a curto e longo prazo" (3).

Estas teorias, entretanto, não podem ser aproveitadas, a menos que possam integrar-se no sistema empresarial. Sendo teorias novas, muitas vêzes exigem informações que ainda não foram obtidas. "Maximizar" lucros por meio da programação linear para utilização de máquinas, por exemplo, só será possível se fôr conhecido o efeito que terá sôbre o lucro a fabricação de cada produto em cada máquina em que possa ser produzido. A aplicação das teorias matemáticas das linhas de espera à programação de transportes exige que o custo do material à espera e o do transporte adicional sejam obtidos numa base diária para os períodos de mudanças freqüentes de programação.

O equipamento para processamento eletrônico de dados tem enorme capacidade de processar as informações que lhe são dadas. Esta capacidade torna desejável a coleta e classificação de novas informações, pois é o computador eletrônico que torna, frequientemente, praticável o uso de complexas teorias científicas.

Qual a relação entre o que acabamos de expor com a contabilidade? A ligação entre estas novas teorias e a contabilidade é a seguinte: a contabilidade é parte do sistema empresarial; é, em si, a implementação de inúmeras "novas teorias" desenvolvidas através de muitos anos de experiência; as novas teorias científicas tornar-se-ão úteis sòmente quando forem integradas nas operações diárias de negócios, isto é, no sistema contábil já descrito. O exemplo que adiante daremos de uma emprêsa típica de fabricação pode servir para indicar de que forma estas novas informações poderão ser fornecidas pelo sistema contábil. Descreveremos algumas das decisões que devem ser tomadas pela emprêsa e as informações que seu sistema contábil fornece rotineiramente para auxiliá-la nessas

(3) «Mathematical Programming, Better Information for Better Decision» - Making, Henderson \& Schlaifer, Harvard Business Review, maio-junho 1954. 
decisões. Apresentaremos, também, uma descrição de diversas teorias científicas que já tiveram sua utilidade demonstrada e de como poderão ser integradas no sistema contábil as informações que essas novas teorias exigem.

\section{Descrição de uma Emprêsa}

Tomemos uma grande emprêsa de fabricação com as seguintes características: grande variedade de produtos vendidos principalmente a fregueses industriais, incluindo fabricação de máquinas para a indústria têxtil e compra e distribuição de peças e equipamento para essa indústria.

Essa companhia tem fábricas que operam com peças e partes componentes produzidas em outras fábricas do grupo e aproximadamente 25 filiais atacadistas que trabalham com grande variedade de produtos.

A companhia deve manter um programa contínuo de novas programações de produtos, bem como iniciar um plano de pesquisa e desenvolvimento, a fim de fazer face à concorrência. A obsolescência de seu estoque de produtos acabados é relativamente significativa. A companhia deve manter um serviço de pronta entrega, principalmente no setor de peças.

Em cada uma das filiais atacadistas, a emprêsa conta com um corpo de vendedores que visitam regularmente os fregueses importantes e mantêm-se em contato com o mercado local a fim de obter informações quanto à expansão industrial do ramo.

Nos territórios em que as filiais atacadistas não têm sido muito eficientes, a companhia mantém representantes.

Êstes estão subordinados a escritórios distritais de vendas que também supervisionam as filiais atacadistas. Os fregueses e clientes em potencial são numerosos e de tipo variado. Os custos de vendas da emprêsa (salários, comissões e despesas de viagens) representam um fator significativo de custo. As despesas com a propaganda são pequenas. O risco de crédito não é, geralmente, fator sério. E necessário, porém, conceder longos prazos de crédito em muitos casos. 
Em suma, esta é uma emprêsa real, atingida por tôda a complexidade e multiplicidade de fatôres que afetam qualquer companhia de fabricação.

\section{Decisões a Serem Tomadas}

Damos abaixo alguns dos problemas a serem enfrentados por essa emprêsa e as decisões a êles relativas que deve tomar.

As decisões que se referem ao contrôle do estoque e da produção incluem : que produtos devem ser mantidos em estoque; que estoque deve ser mantido dêsses produtos; quando acrescentar novos produtos e quantidades de produtos ao estoque; onde localizar o estoque de produtos acabados; qual o número, tamanho e localização de depósitos; como avaliar a obsolescência; o que deve ser estocado e o que deve ser fabricado para atender a pedidos; onde fabricar produtos e peças.

As decisões que se referem às vendas incluem: quantos representantes manter em cada zona; qual é o melhor tipo de vendedor, por exemplo, técnico ou não-técnico; quantos vendedores contratar e como usá-los; quanto e qual o tipo de treinamento a ser oferecido aos representantes; que efeito terão na atual linha de produtos os novos itens propostos; quanto gastar na propaganda e como e onde fazê-la; quais os custos adequados de vendas em cada território e para cada representante.

Outras decisões importantes são: quanto lucro a companhia pode esperar com a melhoria de equipamento e que gastos fará com sua manutenção; qual é a taxa adequada de retôrno sôbre o investimento.

Há, virtualmente, um número infinito de decisões que devem ser e são tomadas por esta companhia para que possa continuar operando. Há muitas decisões nas quais as informações contábeis não serão diretamente utilizáveis, mas essas informações desempenham um papel importante em tôdas as decisões acima mencionadas e muitas outras ainda. As teorias 
científicas têm contribuído para algumas dessas decisões, mas, antes de examiná-las, faremos uma breve análise das informações contábeis rotineiramente utilizadas pela administração. empresarial na tomada de decisões.

Informações Rotineiras que Podem ser Obtidas Através do Sistema Contábil

São muitos os relatórios contábeis preparados para a administração; entre os mais comuns estão as demonstrações dos resultados das operações e da posição financeira da firma. Algumas das informações contidas nessas demonstrações que se relacionarn com as decisões mencionadas - são as seguintes :

\section{A - Resultados de Operações}

1. A demonstração dos resultados de operações mostra o custo das mercadorias vendidas dentro de um padrão derivado e analisa as variações dêsses custos-padrão de fabricação quanto aos custos passíveis de contrôle em relação ao volume e àqueles que, devido à natureza fixa do custo, criam variações em virtude da flutuação do volume.

2. As informações a respeito do lucro por linha de produto são acompanhadas de dados sôbre produtos particularmente importantes.

3. As tendências do custo unitário de produtos importantes são registradas numa base de reposição no mercado. A medida que sobem os preços de mercado da matéria-prima, ou surgem "fatôres de melhoria" na produção horária da mão-de-obra, é registrado o efeito dessas variações no custo unitário do produto.

4. As vendas por território são apresentadas ao lado de tendência das vendas reais e em comparação às quotas de vendas.

5. Incluem-se ainda : pedidos em carteira; custos de vendas - por territórios - e, tanto quanto possível, por linhas de produtos; pormenores adequados sôbre as despesas gerais e de administração; e taxas de retôrno sôbre o investimento. 


\section{$B$ - Posição Financeira}

Além da distribuição apropriada em contas de ativo e passivo, são aqui incluídas as seguintes informações :

1. Análise das transações financeiras que causam variações no capital circulante líquido.

2. Indices especiais, tais como caixa e duplicatas a receber sôbre o passivo a curto prazo; duplicatas a receber em relação ao volume de vendas.

3. Contas importantes de devedores duvidosos.

4. Estatísticas de estoques, tais como rotação (ou índice de estoque sôbre vendas) e informações sôbre produtos obsoletos ou de saída lenta.

5. Aumentos planejados de capital; aprovados - pedidos em andamento - providenciados.

6. Compromissos de compras e sua relação com os planos de produção.

Tôdas estas informações são apresentadas em comparação aos objetivos do orçamento.

\section{C - Outros Dados Fornecidos}

1. Número de produtos com entregas atrasadas em virtude de falta no estoque.

2. Atrasos no atendimento de pedidos.

3. Erros na expedição.

4. Fregueses inativos e perdidos.

5. Custos de engenharia na preparação de ofertas e custos de desenho - por linha de produto.

6. Custos de vendas por vendedores.

7. Custos de expedição por categoria de produtos; custos de manuseio de pedidos; custos de faturamento; custos de armazenamento; todos em têrmos de custo por unidade comparado aos custos-padrão estabelecidos. 
É evidente que estas informações são úteis para a tomada de decisões que mencionamos há pouco. Por exemplo : o nível de estoque de cada produto e as informações sôbre pedidos atrasados, combinados, auxiliam a administração a tomar decisões relativas a níveis de estoque e programas de produção. Fregueses inativos e perdidos, atrasos no atendimento de pedidos, comparações de vendas por território, custos de venda por linhas de produtos e dados de lucros contribuem, todos, para as decisões que se referem ao uso do esfôrço de vendas.

\section{Novas Informações}

Descreveremos, agora, alguns dos tipos de informações necessários para que sejam utilizadas as teorias científicas sôbre o processo de decisão. As teorias que selecionamos já foram aplicadas a problemas reais de negócios. Não tentaremos discutir em pormenor as técnicas mencionadas, porque as mesmas já foram analisadas em outros artigos publicados em diversas revistas, dentre as quais a "Harvard Business Review".

\section{A - Programação da Produção}

Uma das decisões importantes que a emprêsa acima descrita deve tomar se refere à programação das máquinas. A programação linear pode ser aplicada a êste problema. Se o objetivo é "minimizar" o custo de fabricação de certos produtos, é necessário, então, a fim de usar a programação linear, obter uma "tabela de custos" que mostre o custo variável de fabricação de cada peça em cada máquina. Dadas estas informações e certas restrições adicionais - tais como o número de peças de tipos diferentes que podem ser feitas em cada máquina - êste problema pode ser solucionado pela programação linear, através de uma programação por máquina dela deduzida.

Se as quantidades de cada produto fabricado podem ser influenciadás pela emprêsa (como é comumente o caso, até 
certo ponto), o objetivo pode ser a seleção do conjunto de produtos que "maximizará" os lucros. A fim de atingi-lo, o o custo de produção de cada bem deve, na maioria dos casos, ser computado para cada máquina em que possa ser fabricado, assim como o efeito que cada alternativa terá sôbre o lucro.

Em alguns casos, os dados básicos de custo requeridos não estão à mão ou são difíceis de obter. Quando estão à mão, muitas vêzes sua importância pode não ser conhecida e difícil de determinar. O matemático começa com êstes dados de custos ou lucros e com restrições operacionais, determinando, em seguida, tôdas as maneiras possíveis de destinar a produção programada para estas máquinas simultâneamente e calculando qual será o custo ou lucro de fabricação.

\section{$B$ - Contrôle de Estoque}

O contrôle de estoque é outro aspecto importante das decisões. A fórmula da raiz quadrada para o cálculo do lote econômico de compra é conhecida há mais de 20 anos mas ainda não encontra uso generalizado. A teoria moderna de estoque refinou as mais antigas e chegou ao ponto em que, dadas certas informações de custo, podem-se empregar fórmulas que fornecem melhores resultados na forma de determinações mais precisas de quanto e quando comprar (4).

Cada cálculo, entretanto, precisa começar com determinadas quantidades, tais como o custo do capital investido, do manuseio e armazenamento do estoque e de diversas quantidades de compra para estoque. Estas quantidades são difíceis de medir e nem sempre estão à mão.

\section{C - O Uso do Esfôrço de Vendas}

Há, sempre, o problema de como utilizar o esfôrço de vendas dos vendedores do representante. A aplicação clássica da matemática aos problemas de negócios resulta no cálculo

(4) Para um levantamento de algumas dessas importantes publicações neste campo vide: «Looking Around», Harvard Business Review, janeiro-fevereiro 1957. 
do melhor modo de usar um certo montante de esfôrço do. vendedor em relação a diversos fregueses (5). Para fazer êste cálculo, são necessárias as seguintes informações : custo de fazer a visita e montante de vendas efetuadas a cada freguês. Com estas informações básicas, é, em geral, possível classificar os fregueses em grupos por tamanho e determinar o retôrno que se pode esperar de diferentes esforços de vendas. O resultado dêsses cálculos poderia ser a melhor programação do tempo do vendedor, a qual levaria ao aumento de vendas pelo mesmo custo.

\section{$D$ - Manutenção e Renovação de Equipamento}

As descobertas teóricas mais recentes na análise de falhas. no equipamento tornaram possível relacionar a vida e manutenção do equipamento à possibilidade de falha (6). Para aplicar a teoria à companhia que descrevemos, é necessário determinar o custo de manutenção de uma parte do equipamento, o custo projetado, em base anual, de nôvo equipamento e o custo de tempo no qual o equipamento está parädo.

Este último é particularmente difícil de medir e não está, em geral, à disposição, nas emprêsas. Porém, dados êstes. custos, as teorias matemáticas podem ser empregadas para avaliar os custos gerais de diversos programas de manutenção e para o cálculo do período mais econômico para renovação de equipamento.

\section{Integração de Novas Teorias no Sistema Contábil}

Os exemplos dados exigem que sejam fornecidas as seguintes informações financeiras :

1. Custo variável de fabricação de cada produto (ou peça) em cada máquina.

(5) «Optimal Distribution of Effort», B. O. Koopman, Journal of Operations Research Society of America.

(6) Vide, por exemplo, «Failure of Complex Equipment», Gordon Shellard, Journal of the Operations Research Society of America, maio 1953. 
2. Efeito sôbre o lucro por produto atribuivel à fabricação em diferentes máquinas.

3. Custo do capital investido no estoque.

4. Custo de (a) manuseio e (b) armazenamento do estoque.

5. Custo de compra de quantidades diversas de itens para estoque.

6. Custo do esfôrço de vendas e vendas a êle relacionadas para cada vendedor e cada freguês.

7. Custo de manutenção de cada máquina.

8. Custo anual de operação (inclusive depreciação) do equipamento nôvo.

9. Custo do período de tempo em que a máquina não está operando.

É evidente que estas informações são de natureza geral, da mesma forma que as fornecidas pelo sistema contábil descrito anteriormente. Quando podem ser medidas com certa precisão, não há razão para que não sejam rotineiramente fornecidas pelo sistema contábil. Para completar a integração destas novas teorias no sistema contábil, as implicações processuais devem ser traduzidas em têrmos de novas regras de operação e, então, postas em prática.

\section{Informações Não-Rotineiras}

Neste artigo, concentramos nossa atenção na provisão de informações rotineiras para as decisões normais e diárias de negócios. Há, naturalmente, muitas decisões que não são tomadas com essa frequiência. Algumas delas são descritas como de "diretrizes" e outras, pela própria natureza, não surgem todos os dias, como, por exemplo, a localização e construção de um nôvo depósito ou a introdução de um nôvo produto. As decisões dêste tipo são tomadas, atualmente, com base numa variedade de informações, inclusive contábeis. 
Outro tipo de análise que não ocorre freqüentemente é a destinada a fazer uma correção de grande importância. Lucros em declínio podem fazer com que um administrador passe a observar detidamente um certo número de atividades, como, por exemplo, o custo de fabricação de suas linhas de produtos. Ao fazê-lo, o dirigente poderá contratar consultores ou assessôres para elaborarem um estudo minucioso e exigir, nesse estudo, o emprêgo das técnicas e análises científicas mais modernas.

A pesquisa científica pode ser levada a efeito em questões de diretrizes, tais como a de uma companhia continuar a suprir uma só indústria ou optar pela diversificação, assim como em inúmeras decisões especiais tais como as acima mencionadas (7). No decurso dessas decisões, as informações que poderiam ser de maior utilidade estão, muitas vêzes, faltando. Esta situação, entretanto, deve sempre ser esperada até certo ponto, pois haverá sempre certos estudos especiais e imprevistos para os quais dados históricos de utilidade estejam faltando. Quando fôr desejável, estas informações podem ser obtidas numa base temporária e, se econômico, podem ser introduzidas no sistema rotineiro de contabilidade.

Os dirigentes que tomam decisões são ocupados. A contabilidade os auxilia porque fornece informações financeiras e operacionais em grande abundância e em linguagem familiar e precisa. Qualquer que seja o sistema de informações usado por uma companhia, êste deve ser elaborado a fim de dar informações globais e, para ser eficiente, deve utilizar todos. os métodos de coleta, processamento e comunicação destas informações aos administradores encarregados de tomar as decisões. A contabilidade é um sistema de desenvolvimento e apresentação de informações sôbre as operações do negócio e, em alguns casos, de provisão de informações requeridas para problemas especiais e estudos minuciosos e exaustivos de assessoria.

(7) «Operations Research of Top Management», E.O. Boshell, Dunn's Review and Modern Industry, março 1956. 


\section{Conclusões}

\section{Em resumo :}

Primeiro, descrevemos a natureza fundamental da contabilidade e mostramos de que forma desempenha papel vital no processo de decisões.

Segundo, descrevemos de que maneira as teorias científicas sôbre o processo de decisão e o processamento eletrônico de dados trouxeram a necessidade de certas informações novas.

Terceiro, destacamos a semelhança das novas informações necessárias com as já existentes e analisamos a integração destas novas informações no sistema contábil.

Por último, mostramos que a aplicação da eletrônica e de métodos científicos a decisões de negócios não estão em concorrência com a contabilidade, mas, ao contrário, a suplementam. Estas novas descobertas podem ser utilizadas eficientemente através de integração no sistema empresarial.

Contabilidade é a linguagem de negócios e pode ser substituída sòmente por outra linguagem igualmente completa, bem compreendida, flexível e prática. As dificuldades práticas, inerentes ao desenvolvimento de tal linguagem, são assombrosas.

Entretanto, o preço necessário para sobrepujar estas dificuldades práticas teria que ser pago, não se adaptasse a contabilidade aos horizontes mais vastos que as descobertas cada vez mais rápidas da ciência administrativa e a enorme capacidade e flexibilidade do processamento eletrônico de dados estão a trazer ao mundo de negócios.

A contabilidade não tem outra alternativa senão lutar pelo reconhecimento destas novas descobertas e integrar-se naquelas que sejam de utilidade para a emprêsa (8). Todos os fenômenos aqui descritos nos exemplos de novas teorias já fo-

(8) Para alguns comentários sôbre as relaçóes de pesquisa operacional com a contabilidade vide «Operations Research and Accounting», Stafford Beer, Operational Research Quarterly, março 1954. 
ram há muito reconhecidos pelos contadores esclarecidos. Se bem que muitos contadores se preocupam com os difíceis problemas práticos do dia-a-dia, outros há muito estão a par dos inúmeros aspectos de negócios que exigem mais esclarecimentos e deram maior atenção e compreensão a êstes aspectos.

Enquanto isto continuar, a contabilidade será, necessàriamente, um elemento dinâmico, crescente e vital para a emprêsa. 